Journal of Patient-Centered

4-19-2021

\title{
Perioperative Family Updates Reduce Anxiety and Improve Satisfaction: A Randomized Controlled Trial
}

\author{
Lindsay S. Howe \\ Daniel Wigmore \\ Nathaniel Nelms \\ Patrick Schottel \\ Craig Bartlett \\ David Halsey \\ Martin Krag \\ David Lunardini \\ Robert Monsey \\ Bruce Beynnon \\ See next page for additional authors
}

Follow this and additional works at: https://aah.org/jpcrr

Part of the Mental and Social Health Commons, Orthopedics Commons, Quality Improvement Commons, Surgery Commons, and the Surgical Procedures, Operative Commons

\section{Recommended Citation}

Howe LS, Wigmore D, Nelms N, Schottel P, Bartlett C, Halsey D, Krag M, Lunardini D, Monsey R, Beynnon B, Blankstein M. Perioperative family updates reduce anxiety and improve satisfaction: a randomized controlled trial. J Patient Cent Res Rev. 2021;8:107-12. doi: 10.17294/2330-0698.1805

Published quarterly by Midwest-based health system Advocate Aurora Health and indexed in PubMed Central, the Journal of Patient-Centered Research and Reviews (JPCRR) is an open access, peer-reviewed medical journal focused on disseminating scholarly works devoted to improving patient-centered care practices, health outcomes, and the patient experience. 


\section{Perioperative Family Updates Reduce Anxiety and Improve Satisfaction: A}

Randomized Controlled Trial

\section{Authors}

Lindsay S. Howe, Daniel Wigmore, Nathaniel Nelms, Patrick Schottel, Craig Bartlett, David Halsey, Martin Krag, David Lunardini, Robert Monsey, Bruce Beynnon, and Michael Blankstein 


\title{
Perioperative Family Updates Reduce Anxiety and Improve Satisfaction: A Randomized Controlled Trial
}

\author{
Lindsay S. Howe, MD, ${ }^{1}$ Daniel Wigmore, MD, ${ }^{1}$ Nathaniel Nelms, MD,${ }^{2}$ Patrick Schottel, MD, ${ }^{2}$ Craig \\ Bartlett, MD, ${ }^{2}$ David Halsey, MD, ${ }^{2}$ Martin Krag, MD, ${ }^{2}$ David Lunardini, MD, ${ }^{2}$ Robert Monsey, MD, ${ }^{2}$ \\ Bruce Beynnon, $\mathrm{PhD},{ }^{2}$ Michael Blankstein, $\mathrm{MD}^{2}$ \\ ${ }^{1}$ Larner College of Medicine at the University of Vermont, Burlington, VT; ${ }^{2}$ Department of Orthopaedics and \\ Rehabilitation, University of Vermont Medical Center, Burlington, VT
}
Purpose
This study aimed to determine if standardized updates at specific perioperative events affect anxiety and satisfaction of the family members and if the length of surgical procedure affects the satisfaction with updates.

Methods

This study was a randomized control trial. In the control group, surgeons communicated with the family only once near the completion of the procedure. In the intervention group, families received electronic updates at 3 significant perioperative events during the procedure. A postoperative survey rating family member satisfaction and anxiety levels, using a Likert scale of 0-5, was administered.

Results Mean level of overall satisfaction did not differ between groups (intervention: $4.68 \pm 0.69$ [95\% $\mathrm{Cl}$ : 4.50, 4.87]; control: $4.61 \pm 0.78$ [95\% Cl: 4.40, 4.82]; $\mathrm{P}=0.69$ ). Mean anxiety levels were lower in the intervention group $(2.48 \pm 1.43[2.10,2.86])$ than in the control group $(3.12 \pm 1.32$ [2.77, 3.47]; $\mathrm{P}=0.01)$. Mean satisfaction with perioperative updates was higher in the intervention $(4.48 \pm 0.83$ [4.26, 4.70]) versus control group (3.16 \pm 1.89 [2.67, 3.65]; $P=0.0001)$. For all subjects, there was positive correlation between procedure time and anxiety (Spearman's rho: $0.34 ; \mathrm{P}=0.0002$ ) and negative correlation between procedure time and overall satisfaction (Spearman's rho: $-0.23 ; \mathrm{P}=0.01$ ).

Conclusions Anxiety and satisfaction with perioperative updates were significantly improved by additional perioperative updates. These findings indicate that updating families during significant standardized strategic perioperative events can reduce the anxiety of loved ones and are preferred by most families. (J Patient Cent Res Rev. 2021;8:107-112.)

Keywords perioperative updates; perioperative communication; surgery; family-centered care; patient satisfaction

$\mathrm{M}$ ultiple studies have shown that perioperative communication is important in reducing anxiety and improving the overall experience of family members waiting for surgical patients. ${ }^{1-3}$ Perioperative communication and attentiveness have been identified as the two most important determinants of perceived surgeon performance. ${ }^{4}$ Moreover, surgeons agree that perioperative communication is important and describe the patient's family members as pseudo-patients. ${ }^{5}$ A recent study showed that increased perioperative communication increases patient satisfaction after total joint arthroplasty, but there have been no studies conducted using standardized perioperative updates to investigate their effect on family member satisfaction. ${ }^{6}$

Corresponding author: Lindsay S. Howe, MD, 295 Speer Blvd, Apt. 213, Denver, CO 80203 (lindsay.howe@denverem.org)
Communication and empathy are even more important in the case of adverse outcomes. ${ }^{7,8}$ Family members of patients in the intensive care unit rated attitude, clarity of message, and ability to ask questions as most important when receiving bad news. The CARE/SHARE models of establishing rapport with patients and families suggest it is best to wait until all information is available before speaking with the family, particularly in the event of adverse surgical outcomes. ${ }^{9}$ However, presently there is no agreed-upon standardized time to deliver postoperative news to patients' families, with some surgeons delivering news before a procedure is entirely complete.

While there is anecdotal evidence that it may be concerning to patients' families to not receive an update at the scheduled ending time of a procedure, actual family preference remains undetermined. ${ }^{10}$ In a study by Blum et al, families were surveyed regarding perioperative stress and satisfaction regarding the care experience. Those receiving periodic updates (a phone call every 
2 hours) reported less anxiety and a better overall experience than the group of families who did not receive periodic updates. ${ }^{11}$ However, no study currently exists that examines which critical events of the case are most important in surgeon-family communication.

With a focus on patient- and family-centered care, we aimed to determine the effect of strategic communication with patients' relatives during the perioperative period on their satisfaction, anxiety, and overall experience. We hypothesized that updating family members on a greater number of surgical milestones would enhance the satisfaction and decrease the anxiety levels of the loved ones during the perioperative period.

\section{METHODS}

\section{Participants and Randomization}

This study was a prospective randomized controlled trial. All families of patients undergoing inpatient arthroplasty, spine, and trauma procedures during the summer months of 2016 and 2017 were initially included. Exclusions included patients under 18 years of age, non-Englishspeaking patients/families, and patients with families who would not be waiting in the hospital. Informed consent to participate in the study was obtained from the family, and the research protocol was approved by the university's institutional review board.
Patients were 1:1 randomized into one of two groups - a control group and an intervention group - via a random number generator. A total of 165 patients were approached for the study, and 115 met the inclusion criteria. Of the 115 eligible patients, 58 were randomized into the control group and 57 into the intervention group (Figure 1).

In the control group, the surgeon communicated with the family once, near the completion of the surgical procedure. In the intervention group, families received additional standardized electronic updates via pagers at 3 significant perioperative events: 1) initial skin incision has been made; 2) critical part of the case is completed and closure has begun; and 3) closure is complete, and patient will be transferred to the recovery room when ready. These perioperative events were selected as they could be applied to a variety of procedures. Family members were told that they could be communicated with during the procedure, but the exact updates were not discussed regardless of which group they had been randomized. In both groups, the surgeon communicated the final in-person perioperative update at or near the completion of the procedure according to individual surgeon preference. For the intervention group, this inperson update could occur after the second electronic update, which indicated that the critical portion of the procedure was complete and closure had begun, or after the last electronic update, which notified family that

Figure 1. CONSORT flow diagram.

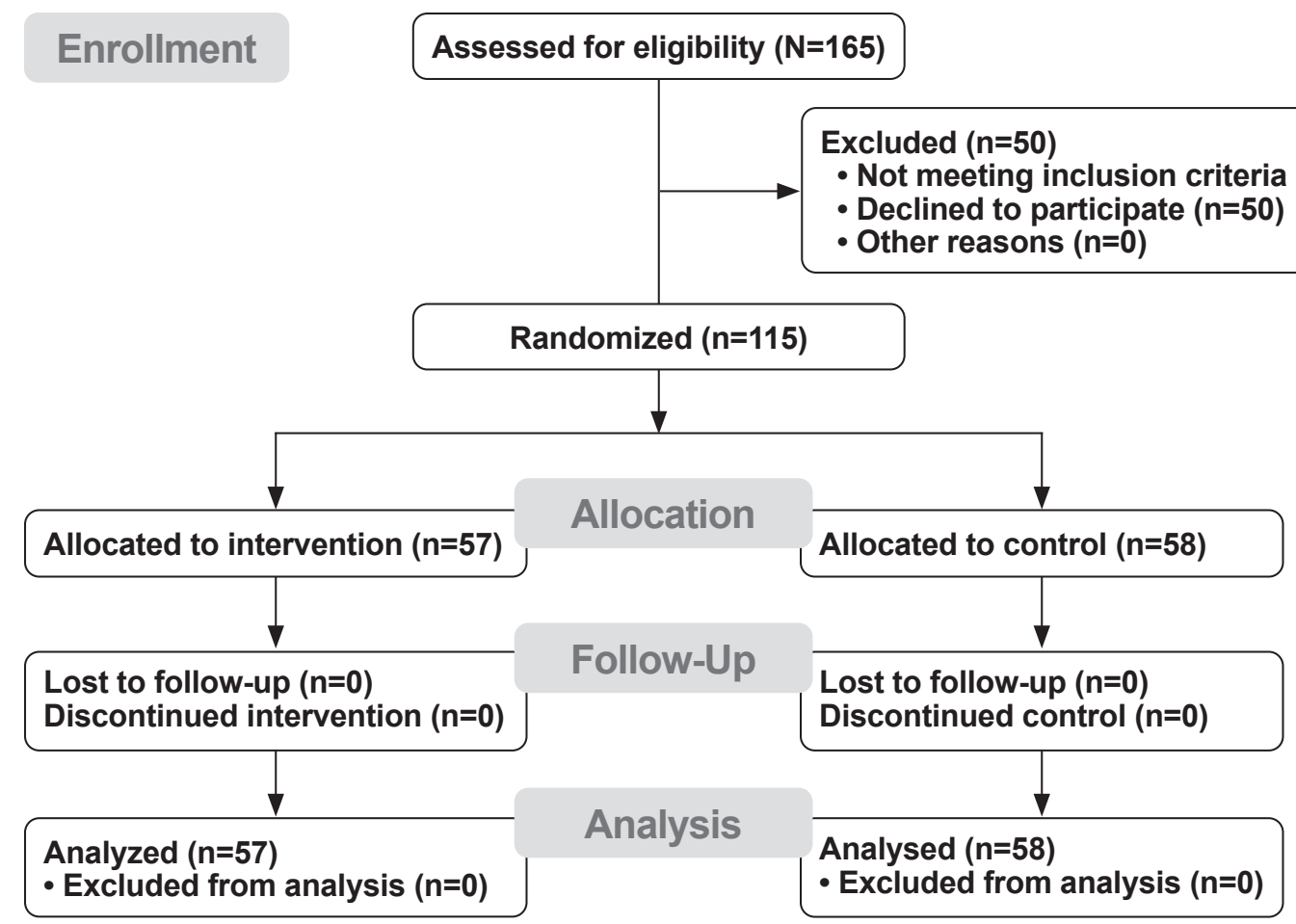


closure had been completed and the patient was preparing for transfer to the recovery room.

\section{Postoperative Survey Administration}

Immediately after the postsurgical surgeon-to-family consult, when both groups had received their final in-person update, a member of the research team administered the postoperative survey designed to rate their satisfaction and anxiety levels using a Likert scale with range of $0-5$ (Online Appendix A). A score of zero was associated with no anxiety and extremely low satisfaction, while a score of 5 was associated with high anxiety and highly satisfied. We adopted a previously validated survey and modified it accordingly. ${ }^{11}$

If multiple family members were present, one would volunteer to independently complete the survey. In addition to the survey questions, basic demographic information of the patient and family member completing the survey was obtained. Once the survey was explained to the family member, the individual was left to complete the survey independently. When the survey was completed, they left it in a secure drop box.

\section{Survey Test-Retest Reliability}

To test for reliability of the survey, we took 10 subjects and called them the day following the original survey. A member of the research team verbally administered the survey via telephone to the subject who completed the perioperative survey, and the ratings for anxiety, overall satisfaction, and satisfaction with updates were compared to the results from the original survey to ensure that the results were reliable and reproducible.

\section{Statistical Analysis}

Comparisons between groups for demographic characteristics were done using $t$-tests and chi-squared tests of independence for continuous and categorical measures, respectively. Comparisons between groups for the outcome of interest, such as levels of anxiety and satisfaction, were done using Wilcoxon rank-sum test. To investigate the relationships between length of procedure and the outcomes of interest, Spearman's correlations were performed. Comparisons between the original survey and validation follow-up telephone surveys for the outcomes of interest were done using McNemar's test or the McNemarBowker test of symmetry. All statistical analyses were performed using $\mathrm{SAS}^{\circledR} 9.4$ software (SAS Institute Inc.). Statistical significance level alpha was set a priori at 0.05 .

\section{RESULTS}

\section{Family Member Demographics}

Sex and age of the family members, relationship of the individual to the patient, and level of education were not statistically significantly different between the two groups (Table 1).

\section{Anxiety and Satisfaction}

When family members were surveyed about their anxiety during the perioperative period, the intervention group was less anxious than the control group. Overall satisfaction with the perioperative experience did not differ between the two groups, although the control group reported being less satisfied with the frequency of perioperative updates when compared to the intervention group. Most family members $(75 \%)$ were satisfied with the detail of the updates, with a minority of family members $(23 \%$ for intervention, $21 \%$

Table 1. Demographic Characteristics of Control and Intervention Groups

\begin{tabular}{|c|c|c|c|}
\hline Demographic & Control & Intervention & $\boldsymbol{P}$ \\
\hline Age of family member, mean \pm standard deviation & $56.41 \pm 12.42$ years & $54.84 \pm 13.81$ years & 0.522 \\
\hline Male gender, n (\%) & $14(24.1 \%)$ & $19(33.3 \%)$ & 0.276 \\
\hline Highest education, n (\%) & & & 0.480 \\
\hline High school degree & $17(29.3 \%)$ & $16(28.1 \%)$ & \\
\hline Vocational degree & $1(1.7 \%)$ & $3(5.3 \%)$ & \\
\hline Associate degree & $11(19.0 \%)$ & $8(14.0 \%)$ & \\
\hline Bachelor's degree & $12(20.7 \%)$ & $19(33.3 \%)$ & \\
\hline Master's degree & $12(20.7 \%)$ & $7(12.3 \%)$ & \\
\hline Professional degree & $5(8.6 \%)$ & $4(7.0 \%)$ & \\
\hline Relationship to patient, $\mathrm{n}(\%)$ & & & 0.293 \\
\hline Spouse & $30(52.6 \%)$ & $28(49.1 \%)$ & \\
\hline Parent & $2(3.5 \%)$ & $7(12.3 \%)$ & \\
\hline Son/Daughter & $14(24.6 \%)$ & $10(17.5 \%)$ & \\
\hline Other & $10(19.3 \%)$ & $11(21.1 \%)$ & \\
\hline
\end{tabular}


Table 2. Likert Scale Results for of Anxiety, Overall Satisfaction, and Satisfaction With Updates Between Control and Intervention Groups

\begin{tabular}{lccc}
\hline Variable & $\begin{array}{c}\text { Control Group, } \\
\text { Mean } \pm \text { SD (95\% CI) }\end{array}$ & $\begin{array}{l}\text { Intervention Group, } \\
\text { Mean } \pm \text { SD (95\% CI) }\end{array}$ & \begin{tabular}{l}
$\boldsymbol{P}$ \\
\hline Level of anxiety
\end{tabular} \\
Overall satisfaction & $3.12 \pm 1.32(2.77,3.47)$ & $2.48 \pm 1.43(2.10,2.86)$ & 0.01 \\
Satisfaction with updates & $4.61 \pm 0.78(4.40,4.82)$ & $4.68 \pm 0.69(4.50,4.87)$ & 0.69 \\
\hline
\end{tabular}

Likert scale (range: $0-5$ ) rating per group is reported as mean \pm standard deviation (SD) with $95 \%$ Cl. Statistical significance was calculated using Wilcoxon rank-sum test (with alpha of $P<0.05$ ).

Table 3. Correlations Between Length of Procedure and Anxiety, Overall Satisfaction, and Satisfaction With Updates

\begin{tabular}{lccc}
\hline Outcome Measure & $\begin{array}{c}\text { Spearman's Rho for } \\
\text { All Subjects }\end{array}$ & $\begin{array}{c}\text { Spearman's Rho for } \\
\text { Intervention Group }\end{array}$ & $\begin{array}{c}\text { Spearman's Rho for } \\
\text { Control Group }\end{array}$ \\
\hline Anxiety & $0.34(\mathrm{P}=0.0002)$ & $0.48(\mathrm{P}=0.0002)$ & $0.30(\mathrm{P}=0.02)$ \\
Overall satisfaction & $-0.23(\mathrm{P}=0.01)$ & $-0.26(\mathrm{P}=0.053)$ & $-0.26(\mathrm{P}=0.054)$ \\
Satisfaction with updates & $-0.11(\mathrm{P}=0.23)$ & $0.03(\mathrm{P}=0.84)$ & $-0.35(\mathrm{P}=0.01)$ \\
\hline
\end{tabular}

Statistical significance was based on alpha of $P<0.05$.

for control) reporting that the updates were too detailed. The mean reported levels of overall satisfaction, anxiety, and satisfaction with updates are reported in Table 2.

\section{Ideal Event Updates}

It was found that most families would like to be updated when the critical part of the case is complete and closure is about to begin (75.7\%), when the closure is complete and the patient will soon be transferred to the recovery room $(67.8 \%)$, and when the patient is actually leaving the operating room $(63.5 \%)$. A majority of family members did not want to be updated when the initial skin incision had been made $(60 \%)$. Regarding the final in-person perioperative update, $52 \%$ of family members preferred this occurred upon the patient's transfer to the recovery room. Also, $53 \%$ of family members stated a preference that all updates be communicated via text message.

\section{Updates and Length of Procedure}

The mean duration of surgery did not differ between groups (198.44 \pm 65.65 minutes [95\% CI: 181.02, 215.86] for intervention vs $183.26 \pm 71.72$ minutes [95\% CI: 164.40, 202.12] for control; $\mathrm{P}=0.12$ ). The Spearman's correlations between length of procedure and main outcomes are depicted in Table 3. For all subjects, there was a negative correlation between length of procedure and overall satisfaction. When the groups were looked at individually, there was no correlation between these variables, but the trends were very similar. In all subjects, there was a positive correlation between length of procedure and level of anxiety. There was a slightly stronger correlation between anxiety and time for those in the intervention group as compared to the control group. Regarding family satisfaction with updates, there was a negative correlation between length of procedure and satisfaction with updates in the control group. There was no significant correlation within the intervention group.

When investigating the effect of the difference between actual surgical time and estimated scheduled time, there was a significant negative correlation between the time difference variable and overall satisfaction for all subjects (Spearman's rho: $-0.33 ; \mathrm{P}=0.0003$ ). There was a significant positive correlation between the time difference and level of anxiety within the intervention group only (Spearman's rho: $0.28 ; \mathrm{P}=0.04$ ). Regarding satisfaction with updates, there was a significant negative correlation with time difference within the control group only (Spearman's rho: $-0.30 ; \mathrm{P}=0.02$ ).

\section{Survey Reliability Per Retest}

When responses to the original postsurgical survey were compared to those of the same survey conducted over the phone the next day, researchers found that the main outcomes (level of anxiety, overall satisfaction, and satisfaction with updates) did not differ (Table 4). All kappa values were $>0.8$, showing excellent reliability. 
Table 4. Validation of Main Survey Outcomes

\begin{tabular}{lcc}
\hline Variable & Kappa & $\boldsymbol{P}$ \\
\hline Level of anxiety & 0.87 & 0.99 \\
Overall satisfaction & 1.0 & 1.0 \\
Satisfaction with updates & 0.81 & 0.99 \\
\hline
\end{tabular}

\section{DISCUSSION}

Studies have shown that perioperative communication is important in reducing anxiety and improving the overall experience of family members waiting for surgical patients, ${ }^{2,5,6}$ but there are no guidelines or recommendations as to how many, or when, updates should be communicated. We aimed to determine the effect of additional electronic updates at significant, standardized perioperative events on family members' anxiety and satisfaction during the perioperative period. We found that standardized updates decreased anxiety, although the level of overall satisfaction with the perioperative experience did not differ between intervention and control groups.

\section{Anxiety and Satisfaction}

The results of this study supported our hypothesis that standardized updates during the perioperative period would decrease the anxiety levels of family members. Interestingly, the level of overall satisfaction of family members in the waiting area was independent of the frequency of updates received during the perioperative period. We believe the levels of overall satisfaction may have been biased by the fact that no unexpected adverse intraoperative complications occurred. In addition, the survey was administered after the postsurgical surgeonto-family update, at which time it was communicated to the loved ones that their family member had a successful procedure and they would be able to visit them soon. Although the level of overall satisfaction was not significantly different between the groups, the intervention group was significantly more satisfied with the number of surgical updates as compared to the control group. These results indicate that family members in the waiting area appreciated being aware of the progress of the procedure.

\section{Updates and Procedure Length}

Regarding procedure length, all subjects were more anxious and less satisfied during longer procedures. When comparing groups, as the procedure length increased, the intervention group had a greater increase in anxiety than the control group, although the intervention group was less anxious overall. It could be theorized that once an individual has received 2 or 3 updates, it may be anxiety-provoking to have to wait an extended period before the next update arrives. This suggests that the timing and frequency of updates may be more important than standardizing updates by type of perioperative event. If family members were to receive updates at hourly or bihourly intervals - eg, to communicate that the procedure is progressing well or as planned - it may relieve some of the added anxiety. Additionally, the control group became increasingly less satisfied with updates as the procedure time increased. This suggests that frequent updates are most likely to increase family satisfaction during procedures of extended length. In future studies, it would be interesting to investigate the time point at which family satisfaction begins to decrease. This could aid in the development of procedure-specific standardized perioperative updates.

\section{Study Limitations}

This study has several limitations. Similar to procedure length, the type of procedure (ie, arthroplasty vs spine, or trauma) also may affect anxiety and satisfaction due to varying degrees of acuity and surgical risk. No subgroup analysis was performed, as some groups were too small to draw conclusions. Furthermore, individual surgeons vary in communication styles, and the anxiety and satisfaction of family members would likely be influenced by their relationship with the surgeon. A subgroup analysis of the individual surgeons was not conducted as part of this study.

No adverse events or perioperative complications occurred during this study, which may bias the postsurgical anxiety and satisfaction levels reported. If the survey was administered prior to the postoperative surgeon-to-family consultation, the reported anxiety and satisfaction may have been different. We did not collect data during the preoperative consultation, nor were these consultations standardized, so the practices of individual surgeons during these meetings may have affected the relationship between the family member and the surgeon. These varying relationships likely affected the anxiety and satisfaction felt during the perioperative period.

Additionally, only one family member performed the postsurgical survey. For those patients who had more than one family member present during the perioperative period, we allowed a family member to volunteer to complete the survey. To keep family members blinded to the assigned groups, it was not asked how many updates they received, so it is possible that a different family member was holding the pager and did not inform all family members of the updates. Furthermore, a baseline anxiety level was not reported during the preoperative period. In future studies, it will be important to collect baseline anxiety levels, as an individual who is highly anxious at baseline will likely report higher anxiety levels 
during the perioperative period, regardless of updates or experience. Another limitation of this study is the outcome measure that was used. The research team discussed the importance of evaluating internal and external validity (content validity, criterion validity, and construct validity) of the outcome. Although formal validity studies were not performed, we adapted a previously validated survey, modifying it appropriately for our study. ${ }^{11}$ Survey testretest reliability was performed as an adjunct, however, it potentially may have been underpowered. Future work will be focused on further validating the survey.

Although statistically significant, the differences in levels of anxiety, overall satisfaction, and satisfaction with updates were small. We are unable to quantify the clinical significance of this, and additional studies with a larger sample size are needed to determine clinical significance. The next step would be to perform the necessary survey validation studies prior to its use in future studies.

\section{CONCLUSIONS}

The results from this study suggest that if updates are provided to family members at standardized perioperative events, their anxiety levels will be reduced and their overall experience in the waiting area enhanced. There are clear benefits to providing standardized perioperative updates to family members in surgical waiting areas, especially for longer procedures, though the ideal timing and intervals of these updates is not yet known. Future studies could target expanding the intervention across surgical subspecialties as part of improving quality of patient- and family-centered care.

\section{Patient-Friendly Recap}

- Family members of patients undergoing surgery can experience high levels of anxiety while in the waiting room.

- Authors conducted a randomized control trial to test whether family members preferred receiving multiple text message updates at specific stages of the procedure versus being updated only when the surgery was nearly complete.

- Family-reported anxiety levels were lower in the group receiving multiple text message updates as the surgery progressed.

-While most family members expressed strong satisfaction with being updated throughout the procedure, this group was not significantly more satisfied in the care experience overall than those not receiving perioperative updates. More research on this intervention is warranted.

\section{Acknowledgments}

We thank Michael DeSarno for aiding in the statistical analysis of this work.

\section{Author Contributions}

Study design: Howe, Beynnon, Blankstein. Data acquisition or analysis: all authors. Manuscript drafting: Howe, Wigmore, Blankstein. Critical revision: all authors.

\section{Conflicts of Interest}

None.

\section{References}

1. Davis Y, Perham M, Hurd AM, et al. Patient and family member needs during the perioperative period. J Perianesth Nurs. 2014;29:119-28. CrossRef

2. Gordon CR, Rezzadeh KS, Li A, et al. Digital mobile technology facilitates HIPAA-sensitive perioperative messaging, improves physician-patient communication, and streamlines patient care. Patient Saf Surg. 2015;9:21. CrossRef

3. Herd HA, Rieben MA. Establishing the surgical nurse liaison role to improve patient and family member communication. AORN J. 2014;99:594-9. CrossRef

4. Schmocker RK, Cherney Stafford LM, Siy AB, Leverson GE, Winslow ER. Understanding the determinants of patient satisfaction with surgical care using the Consumer Assessment of Healthcare Providers and Systems surgical care survey (S-CAHPS). Surgery. 2015;158:1724-33. CrossRef

5. Jordan AL, Rojnica M, Siegler M, Angelos P, Langerman A. Surgeon-family perioperative communication: surgeons' selfreported approaches to the "surgeon-family relationship." J Am Coll Surg. 2014;219:958-67. CrossRef

6. Day MA, Anthony CA, Bedard NA, et al. Increasing perioperative communication with automated mobile phone messaging in total joint arthroplasty. $J$ Arthroplasty. 2018;33:19-24. CrossRef

7. Gilbey P. Qualitative analysis of parents' experience with receiving the news of the detection of their child's hearing loss. Int J Pediatr Otorhinolaryngol. 2018;74:265-70. CrossRef

8. Jurkovich GJ, Pierce B, Pananen L, Rivara FP. Giving bad news: the family perspective. J Trauma. 2000;48:865-70. CrossRef

9. Taylor D, Hassan MA, Luterman A, Rodning CB. Unexpected intraoperative patient death: the imperatives of family- and surgeon-centered care. Arch Surg. 2008;143:87-92. CrossRef

10. Stone AM, Lammers JC. The uncertainty room: strategies for managing uncertainty in a surgical waiting room. Perm J. 2012;16:27-30. CrossRef

11. Blum EP, Burns SM. Perioperative communication and family members' perceived level of anxiety and satisfaction. ORNAC J. 2013;31:14, 16-9, 34-6, passim.

(C) 2021 Advocate Aurora Health, Inc. 